\title{
A INTRODUÇÃO DA RACIONALIDADE CIENTÍFICA NA PRODUÇÃO E NA EDUCAÇÃO EM SÃO PAULO'
}

\section{THE INTRODUCTION THE SCIENTIFIC RATIONALITY IN THE PRODUCTION AND EDUCATION IN SÃO PAULO}

\author{
Manoel Nelito Matheus Nascimento*
}

\begin{abstract}
RESUMO
Este trabalho analisa o processo de introdução da racionalidade científica na produção e na educação no estado de São Paulo nas décadas iniciais do século $\mathrm{XX}$, quando empresários e intelectuais promoveram a inclusão dos princípios tayloristas no Brasil, na produção e na formação tecnoprofissional. Aracionalização das atividades humanas associada ao uso de métodos e instrumentos da higiene, fisiologia e psicologia visava a ter o homem certo no lugar certo com vistas a obter o máximo de produtividade. Nas escolas técnicas, foram introduzidos os testes de seleção ou provas psicotécnicas com a finalidade de classificação dos alunos de acordo com as aptidões requeridas pela indústria. Como forma de ampliar o controle da classe trabalhadora e aumentar a produtividade, foram desenvolvidas experiências na Escola Profissional de Mecânica (EPM) e no Serviço de Ensino e Seleção Profissional (Sesp), organizado pela Estrada de Ferro Sorocabana em 1930. Os responsáveis pelas atividades desenvolvidas em torno da instrução racional e do movimento pela administração científica se organizaram e fundaram, em 1931, o Instituto de Organização Racional do Trabalho (Idort). Em 1934, o Centro Ferroviário de Ensino e Seleção Profissional (Cfesp) foi criado por decreto estadual, e constituído pelas ferrovias e pelo governo do estado de São Paulo. O avanço na aplicação da organização científica do trabalho no ensino técnico provocou, ao longo da década de 1920, o debate sobre a qualificação do trabalhador, contrapondo duas posições. Uma representada pelos defensores da formação integral do operário e outra, pelos liberais reformadores e os educadores da renovação educacional que defendiam a racionalização da educação. No início da década de 1930, a hegemonia dos liberais reformadores e dos educadores da renovação educacional possibilitou que as contribuições de Roberto Mange fossem introduzidas na rede pública de ensino profissional por meio do Código de Educação implantado por Fernando de Azevedo em 1933. O processo de racionalização da formação tecnoprofissional se consolidou em 1942, com a Lei Orgânica do Ensino Industrial, que organizou um sistema de ensino profissional para a indústria e a criação do Serviço Nacional de Aprendizagem Industrial (Senai), transferindo para o setor privado a responsabilidade pela formação e a qualificação da mão de obra necessária para a expansão da industrialização.
\end{abstract}

Palavras-chave. História da educação. Trabalho e educação. Racionalidade científica.

\footnotetext{
Este texto é parte da tese de doutorado intitulada História, trabalho e educação: Relações de produção e qualificação da força de trabalho na agroindústria canavieira, defendida junto à Faculdade de Educação da Unicamp, em 2009.

* Doutor em educação pela Faculdade de Educação da Unicamp e professor do Departamento de Educação da Universidade Federal de São Carlos (UFSCAR) e do PPGE.<mnelito@yahoo.com.br>
} 


\begin{abstract}
This paper analyzes the process of introduction of scientific rationality in production and in education in the State of Sao Paulo in the early decades of the 20th century, when industrialists and intellectuals promoted the inclusion of Taylorist principles in Brazil, in the production and training of technical professionals. The rationalization of human activities associated with the use of methods and instruments of hygiene, physiology and psychology aimed at having the right man in the right place in order to achieve maximum productivity. In technical schools screening tests or psychological evidence exams were introduced with the purpose of classifying students according to the skills required by industry. As a way of extending the control of the working class and increase productivity experiments were carried out in the Professional School of Mechanics (EPM, in the Portuguese acronym) and the Teaching Service and Professional Selection (Sesp, in the Portuguese acronym), organized by the Sorocabana Railroad Company in 1930. Those responsible for activities around the investigation of the movement for rational and scientific management organized and founded in 1931 the Institute of Rational Organization of Work (Idort, in the Portuguese acronym). In 1934, the Railroad Teaching Center and Professional Selection (Cfesp, in the Portuguese acronym) was established by the railroad companies and the Government of the State of Sao Paulo. Advancements in the implementation of the Scientific Organization of Work in technical education caused over the 1920s the debate on the qualifications of the employee, with two opposing positions. One position represented by advocates of workers' integral education; the other position was defended by liberal reformers and educators that advocated the rationalization of education. In the early 1930s, the hegemony of liberal reformers and educators involved with the educational reform enabled the contributions of Roberto Mange to be introduced in public vocational education through the Education Code implemented by Fernando de Azevedo in 1933. The process of rationalization of technical and professional training was consolidated in 1942 with the Organic Law of Industrial Education (Lei Orgânica do Ensino Industrial), which organized a system of vocational education for industry and the creation of the National Service of Industrial Learning (Senai, in the Portuguese acronym), transferring to the private sector the responsibility for the training and qualification of manpower needed for the expansion of industrialization.
\end{abstract}

Keywords: History of Education. Labor and education. Scientific rationality.

\section{Introdução}

Este trabalho analisa a introdução da racionalidade científica na produção e na educação no estado de São Paulo, no desenvolvimento da indústria nas décadas iniciais do século XX.

No Brasil das primeiras décadas do século $\mathrm{XX}$, a expansão da indústria ocorreu sobretudo a partir da Primeira Guerra Mundial, pelas dificuldades de importação de produtos básicos, que motivaram o surgimento de novos estabelecimentos industriais para a produção local.
O proletariado industrial brasileiro era constituído, majoritariamente, por imigrantes, que vieram trabalhar nas atividades rurais, em especial na expansão da produção cafeeira, mas, por causa dos problemas de adaptação e do tratamento recebido nas fazendas ou das periódicas crises na produção cafeeira, muitos desses trabalhadores rurais transferiam-se para os centros urbano-industriais em busca de colocação nas nascentes indústrias e melhores condições de vida.

Para Antonacci, essa fase de expansão da indústria se realizou baseada em relações produtivas 
"sem fundamentações, explicitações e vínculos precisos, de forma empírica, descontínua e desordenada" (ANTONACCI, 1993, p. 36). Da mesma maneira, as relações de trabalho não tinham regras e possibilitavam a superexploração dos trabalhadores pelo capital, em condições péssimas, com longas jornadas diárias, que podiam chegar a 15 horas, assim como a exploração do trabalho de mulheres e crianças.

Em geral, o aumento da produtividade era obtido por meio da "intensificação da cadência das máquinas e da coação extraeconômica e violenta (castigos corporais, ameaças, dispensas do emprego, multas, rígida disciplina do trabalho, etc.)" (HARDMAN; LEONARDI, 1991, p. 136).

A respeito da fase inicial de desenvolvimento da indústria brasileira, Hardman e Leonardi observam não haver diferenças significativas entre os relatos dos cronistas locais, dos viajantes estrangeiros e dos militantes operários e as descrições clássicas de Marx e Engels sobre a evolução industrial europeia.

[...] o proletariado estava ainda nos estágios embrionários de sua formação como classe social distinta. A vida operária era um misto de superexploração na fábrica, repressão policial nos momentos decisivos e controle social e ideológico nas ruas e na cidade. $\mathrm{O}$ proletariado era concebido pelas classes dominantes e pelo Estado como pura força de trabalho. A exploração econômica e a opressão política de classe atingiam não só os proletários - como produtores diretos de mais-valia - mas, de modo mais amplo, o conjunto das massas pobres do campo e das cidades brasileiras. Colonos, parceiros, camponeses minifundiários e posseiros constituíam uma ampla massa de despojados nas zonas rurais, vítimas diretas da exploração latifundiária e da expansão do capitalismo no campo. E, nas cidades, operários imigrantes, desempregados, ex-camponeses, artesãos, doentes, andarilhos, prostitutas, setores pauperizados da baixa classe média, etc. formavam um grande exército de "deserdados da fortuna", que chegava a constituir cerca de $70 \%$ da população urbana. Esse conjunto heterogêneo das massas populares citadinas, característico de sociedades pré-industriais, como a Europa no período de transição para o capitalismo fabril, foi designado na Grã-Bretanha como "turba urbana", estando na raiz de várias revoltas e insurreições de massa. No Brasil, devido ao incipiente crescimento industrial, o chamado "zé povinho" era ainda uma marca do pequeno grau de diferenciação social interna às classes dominadas. Revoltas diversas, como a da vacina obrigatória, no Rio, em 1904, tiveram essas massas populares como atores. (HARDMAN; LEONARDI, 1991, p. 147).

A reação dos trabalhadores à exploração desumana exercida pelo capital foi organizada nos sindicatos, com a realização de greves e movimentos reivindicatórios, na luta por salários melhores e mudanças nas condições de trabalho. O movimento crescente do proletariado em defesa de seus interesses, particularmente por meio de greves, como as realizadas em São Paulo em 1906 e 1907, na luta pelas oito horas de trabalho, o movimento de 1912 e a greve geral de 1917, que surpreendeu às classes dominantes. Conforme análise de Ghiraldelli Junior sobre o movimento operário e a educação no início do século XX,

[...] alguns políticos tentaram explicar o fato dizendo que tais ideias e reivindicações eram "importadas", "coisas do Velho Mundo", e que não cabiam dentro dos "lares honestos" do trabalhador brasileiro. O governo, não raro, encarava o movimento operário nascente como obra insurreicional de "agitadores estrangeiros". (GHIRALDELLI JUNIOR, 1987, p. 46).

Um pequeno grupo de industriais e intelectuais, percebendo a situação de conflito entre os trabalhadores e o capital, iniciou a discussão e a sistematização de propostas de organização do trabalho respaldadas na ciência e na razão como forma de se contrapor ao movimento operário, assumir o controle social e promover o aumento da produtividade nas fábricas. Estes industriais e intelectuais viam "além da perspectiva de restauração da normalidade fabril, a possibilidade de formar novo trabalhador e empresário, novas relações de dominação e reorganização social, ao lado de nova mentalidade no trato dos negócios e da vida pública" (ANTONACCI, 1993, p. 36).

Os empresários defensores da modernização da produção industrial no Brasil como forma de eliminar as dificuldades nas relações de trabalho receberam acusações de outros industriais de estarem plantando a semente da luta de classes.

Até meados da década de 1910, o empresariado ainda evidenciavamaior interesse pelos trabalhadores 
imigrantes para compor a força de trabalho por terem eles experiência e conhecimentos que facilitavam a entrada imediata na produção fabril. No entanto, à medida que o movimento dos trabalhadores crescia como reação à superexploração da força de traba1ho, o interesse do empresariado pelo trabalhador imigrante decrescia, por ser considerado rebelde e ter ideias nefastas aos interesses do empresariado. A mobilização dos trabalhadores imigrantes na organização de sindicatos e na promoção de greves para lutar por seus interesses em melhorar as "condições de trabalho, dos salários, na redução das horas de trabalho diário, na regulamentação do trabalho infantil e feminino, incomodava ao empresariado, que passou a considerá-los como trabalhadores inconvenientes" (CUNHA, 2000c, p. 6). Diante do maior poder de organização e de luta dos trabalhadores imigrantes no início da década de 1920, o empresariado já defendia a sua substituição pelos nacionais, por considerá-los dóceis e obedientes.

Com isso, o empresariado muda o foco de interesse para o trabalhador nacional, até então desprezado, que passa a ser considerado por ser mais dócil, apesar de menos qualificado para o trabalho. Sobre os trabalhadores nacionais havia o preconceito de serem considerados com menor aptidão e qualificação para o trabalho nas fábricas, além de serem acusados de pouca disposição para o trabalho.

A opção pelo trabalhador nacional implicava a necessidade de se iniciar uma empreitada de valorização desse trabalhador cuja "inaptidão e inconstância já não era vista como natural, senão como resultado da falta de oportunidades" (CUNHA, 2000c, p. 6).

De modo geral, associado ao ideário republicano de estabelecimento de uma nova ordem social, com a formação do "homem novo" e do "país novo", a educação foi eleita como o principal instrumento de transformação da sociedade brasileira.

Nesse sentido, a burguesia considerava que o processo de valorização se daria por intermédio de escolas de qualificação para o trabalho, porém não mais com objetivos assistencialistas e sim dentro dos requisitos da indústria moderna da época, isto é, formar para o trabalho nos moldes da organização do trabalho, seguindo os princípios tayloristas:

Ao mesmo tempo em que se dava essa mudança ideológica, as exigências acarretadas pelo próprio processo produtivo, tanto na indústria quanto nos transportes ferroviários, passaram a exigir trabalhadores dotados de qualidades que não poderiam resultar de processos aleatórios. Eles deveriam atender aos requisitos do taylorismo, para o que se impunha sua seleção mediante exames psicotécnicos. A aptidão e a escolha dos melhores foram dois critérios inseridos na prática e no discurso do ensino profissional, sem precedentes no país. (CUNHA, 2000c, p. 6).

Nesse contexto de mudanças, a organização científica da produção passou a ser adotada por um pequeno grupo de empresários como forma de reação aos movimentos grevistas, procurando acabar com o confronto hostil entre patrões e trabalhadores. Dessa forma, além da moderação das tensas relações entre o capital e o trabalho, seriam resolvidos os problemas de horários de trabalho, salários, ritmos da produção, condições gerais de trabalho etc.

Em São Paulo, na década de 1920, um grupo de jovens industriais, engenheiros, médicos, educadores e jornalistas passou a realizar debates e experiências em torno da organização racional do trabatho e do controle dos trabalhadores, com base em soluções orientadas pelos princípios do taylorismo. Eles acreditavam que o fator problemático da produção industrial era "a carência de elementos humanos suficientemente instruídos e capacitados das suas vantagens" ou que "as principais dificuldades encontradas na organização da indústria nacional foram a seleção e o preparo da mão de obra" (ANTONACCI, 1993, p. 62).

Para os membros desse grupo, que finalmente haveriam de se aglutinar no Idort, os métodos científicos eram um meio de reorganizar não apenas a indústria mas toda a sociedade brasileira. Educadores proeminentes como Lourenço Filho e Fernando de Azevedo consideravam os métodos científicos como uma chave para reformar o arcaico e inadequado sistema de educação pública. Sanitaristas como Geraldo de Paula Souza e Moacyr Álvaro [...] consideravam os métodos racionais de saneamento e a organização científica da vida cotidiana como uma solução para eliminar os problemas de saúde. E engenheiros como Gaspar Ricardo Júnior e Roberto Mange consideravam a aplicação de métodos racionais à capacitação e aprendizagem profissional como a chave para a formação de uma força de trabalho mais disciplinada e mais qualificada. (WEINSTEIN, 2000, p. 46). 
Entre os entusiastas da racionalização, tiveram papel proeminente o empresário e engenheiro Roberto Simonsen, o engenheiro e educador Roberto Mange e o educador Lourenço Filho, que deram significativas contribuições para o processo de introdução dos princípios tayloristas no Brasil. Como estudioso da racionalização e empresário preocupado com o aumento da produtividade nas atividades industriais, Roberto Simonsen tinha o controle social como uma das grandes prioridades, especialmente após a greve geral de 1917. Defendia ele (cf. WEINSTEIN, 2000, p. 36) a necessidade de os industriais terem outra visão de industrialização, que superasse as relações de produção arcaicas que muitos insistiam em manter:

A filosofia fordista apresentava a fábrica como um modelo para toda a sociedade e considerava a burguesia industrial, aliada a um corpo de gerentes tecnicamente competentes, a classe mais capacitada para cumprir o dever cívico de uma elite moderna, dada a sua competência técnica e sua posição estratégica no campo da produção. Para um industrial-engenheiro como Simonsen, tentando vigorosamente descartar a velha imagem do plutocrata pançudo, a indústria organizada racionalmente e a administração científica eram um perfeito remédio para os males econômicos e sociais do Brasil. (WEINSTEIN, 2000, p. 40).

Como professor de mecânica da Escola Politécnica, Roberto Mange defendia a utilização de métodos científicos de treinamento para o trabalho e condenava o método tradicional de aprendizagem por se realizar ao acaso e de forma empírica. Considerava que

[...] para mudar esse sistema, pois, era transferir pelo menos parte do processo de treinamento e aprendizagem do local de trabalho para escolas ou cursos administrados por especialistas em educação profissional. [...] para tornar esse processo mais rápido e mais científico, seriam necessários novos métodos de instrução. Além disso, o treinamento deveria incluir alguma forma de instrução para moldar um bom caráter moral, fazendo com que os trabalhadores se identificassem com o progresso industrial. Numa entrevista de 1926, Mange ressaltou que "o operário de hoje [...] tem de ser também cidadão esclarecido, consciente de seus deveres [...]. (WEINSTEIN, 2000, p. 48).
Em 1923, Roberto Mange teve a oportunidade de implementar seu projeto de capacitação profissional no curso de mecânica prática criado pelo Liceu de Artes e Ofícios. Assessorado por médicos e higienistas do Instituto de Higiene, deu início à introdução de métodos psicofísiológicos de seleção no treinamento profissional. A partir de 1925, o curso de mecânica foi transformado em Escola Profissional de Mecânica, com projeto de Roberto Mange, que deu continuidade às experiências de aplicação dos princípios tayloristas na formação dos trabalhadores (ANTONACCI, 1993, p. 64). Nesse curso, Mange introduziu

[...] o sistema de aprendizagem das "séries metódicas", que permitia ao aprendiz avançar da tarefa mais simples para a mais complexa de forma ordenada, aprendendo os "princípios teóricos" subjacentes a cada tarefa no próprio momento em que executava o trabalho. Mange afirmava que esse tipo de treinamento era mais rápido que as técnicas tradicionais, e que a aprendizagem simultânea de princípios teóricos e habilidades manuais era a solução para o "empirismo nefasto". (WEINSTEIN, 2000, p. 51).

Essa primeira experiência de ensino tecnoindustrial nos moldes da Organização Científica do Trabalho foi determinante para o desenvolvimento do ensino profissional no Brasil, como assinala Cunha:

Na criação da Escola Profissional Mecânica, nos empreendimentos dela derivados e até a criação do Senai, foi preponderante a participação de Roberto Mange, engenheiro suíço convidado para lecionar na Escola Politécnica de São Paulo. Mange e outros engenheiros da Escola Politécnica, entre eles Armando de Salles Oliveira, destacaram-se na divulgação da doutrina da Organização Racional do Trabalho, sistematizada por Frederick Taylor, a ponto de, em 1931, fundarem com o patrocínio da Associação Comercial e da Federação das Indústrias de São Paulo, o Instituto de Organização Racional do Trabalho. O Idort passou a ganhar influência à medida que os efeitos da crise econômica de 1929 se somavam aos (efeitos dos) movimentos reivindicatórios de trabalhadores na diminuição da taxa de lucro. (CUNHA, 2000c, p. 24-25).

Para Mange, as novas práticas de ensino profissional permitiam, por um lado, articular-se com as lutas sociais, como estratégias desenvolvidas 
diante das resistências operárias e perante o avanço de suas conquistas sociais, respondendo a anseios e reivindicações em torno de educação, emprego, formação técnica, melhoria das condições de trabalho e de remuneração. Por outro lado, a racionalização das atividades humanas associada ao uso da fisiologia e da psicotécnica visava a ter (cf. ANTONACCI, 1993, p. 65) the right man in the right place, ${ }^{2}$ com vista a se obter o máximo de produtividade:

Dar novo conteúdo ao trabalho, difundir novos conceitos de trabalhos, produzir práticas de ensino e de profissionalização adequadas às exigências de execução de trabalhos repetitivos e precisos, formar trabalhadores para esse tipo de trabalho e construir instrumentos para operacionalização desses objetivos foram perspectivas que se entrecruzaram, nessa experiência de ensino profissional racional em São Paulo. Para formar trabalhadores aptos ao novo tipo de trabalho, foram utilizados dois instrumentos básicos: a série metódica de desenhos e os testes de exame e controle de aptidões. Enquanto os testes psicotécnicos são utilizados para selecionar e desenvolver aptidões psicofisiológicas, analisando, treinando e conformando as habilidades necessárias a cada tarefa; as séries metódicas de desenhos servem para guiar "racionalmente" o aprendiz, "para executar peças com medidas certas, para trabalhar com exatidão" e com "disciplina no método de trabalho". (ANTONACCI, 1993, p. 66).

Os técnicos utilizavam métodos e instrumentos de higiene, fisiologia e psicologia para conhecer, classificar, selecionar e distribuir os trabalhadores na produção de acordo com as habilidades e capacidade individuais adequadas às operações necessárias aos ritmos e movimentos das máquinas.

O discurso científico, orientador da adaptação do homem à máquina, estabelecia novas relações no processo de trabalho e justificavam as práticas educacionais defendidas por Mange:

As máquinas, na sua maioria, possuem certa periodicidade de movimentos que deve formar com o ritmo específico do mecânico um conjunto harmônico. Daí resultarem, de um lado, condições especiais de construção das máquinas [ ...] e, de outro lado, educação das aptidões do mecânico que deve acompanhar e se incorporar à periodici- dade de movimentos da máquina. (MANGE apud ANTONACCI, 1993, p. 67).

Como forma de sujeição dos trabalhadores e obtenção do homem certo para o lugar certo, foram introduzidos os testes de seleção ou provas psicotécnicas com a finalidade de classificar os alunos de acordo com as aptidões requeridas pelo sistema, controlando e avaliando sua educação conforme o tipo de trabalho-tarefa. Coube a Roberto Mange promover o treinamento dos trabalhadores com base na "repartição e especialização do trabalho, de acordo com o sistema Taylor", enquanto os demais técnicos compuseram os testes psicotécnicos aplicados na seleção dos trabalhadores:

Pretendendo produzir um trabalhador moral e tecnicamente adequado às exigências de máxima eficiência com mínimo de desperdício, recompuseram o trabalho, submeteram a aprendizagem a suas normas e, lançando bases para a produção em massa em São Paulo, encaminharam meios para padronização dos modos de trabalhar e de formar trabalhadores em série. [...] Viabilizando a instrução racional escolar e o rápido treinamento de aprendizes, por tarefa/função, esses técnicos desvalorizavam experiências operárias de transmissão de saberes e habilidades na oficina como a qualificação por ofício. Ainda mais, abriram frentes para romper formas de autonomia e controle de trabalhadores organizados, que potencializavam seus próprios meios de substituição. E, pelo registro de seus procedimentos, em que visaram profissões específicas, entende-se que enfrentaram, racionalmente, habilidades técnicas de determinados artífices; provavelmente dos que representavam pontos de estrangulamento para expansão do domínio fabril. (ANTONACCI, 1993, p. 67-70).

Os participantes do grupo defensor da racionalização na organização do trabalho deixaram

[...] registrados inquéritos esquadrinhadores de hábitos, comportamentos e tendências sociais de seus habitantes, conforme recortes específicos apreende-se que, a atividades do grupo Mange inseriram-se em contexto de diversificados exercícios de análise e recomposição social, em que foram produzidos conhecimentos, conformados campos de saber e construídos instrumento de intervenção social. (ANTONACCI, 1993, p. 72).

\footnotetext{
2 "O homem certo no lugar certo".
} 
Nesse sentido, em meados da década de 1920 o educador Lourenço Filho realizou alguns inquéritos, como o intitulado Um inquérito sob o que os moços leem, com o objetivo de investigar os hábitos de leitura de alunos de escolas paulistas. Na mesma linha (ANTONACCI, 1993, p. 72), o educador Fernando de Azevedo promoveu o Inquérito sobre instrução pública em São Paulo, realizado em 1926, por encomenda do jornal $O$ Estado de S. Paulo, para promover direcionadas transformações nas práticas pedagógicas e na organização escolar:

No interior de vasto movimento de regeneração e moralização social através da educação, que conquistara terreno desde críticas aos percalços da república - avaliados, entre outros aspectos, pelos "milhões de analfabetos de letras e ofícios" - e que originou a fundação da Associação Brasileira de Educação, em 1924, no Rio de Janeiro, Lourenço Filho propunha adequar o ensino e a escola às necessidades de progresso e bem-estar nacional "pela prática de novas técnicas que se ensaiam e apuram, com critério científico". Atento a temas como "função social da escola", "recursos científicos de organização e controle do trabalho docente, projetou alterar a educação brasileira "nos seus intuitos e processos", por intermédio de transformação que, além de "intenções administrativas", "estará, mais que tudo, na formação de uma nova mentalidade dos que educam, pais e mestres". U1trapassando o "taylorismo na escola", com suas "inovações que visam dar maior rendimento escolar do ponto de vista da organização das classes". (ANTONACCI, 1993, p. 73).

Como forma de ampliar o controle da classe trabalhadora e aumentar a produtividade, os resultados das experiências conduzidas na Escola Profissional de Mecânica foram aplicados, de maneira sistemática, no Serviço de Ensino e Seleção Profissional (Sesp), organizado pela Estrada de Ferro Sorocabana em 1930. Neste serviço, foram adotadas algumas práticas, como a introdução de exames psicotécnicos para selecionar os "mais capazes" e a instituição do ensino sistemático de ofícios para apressar e baratear a formação profissional. Era a incorporação das "práticas pedagógicas e psicotécnicas que se divulgavam e aplicavam antes mesmos da criação do Idort” (CUNHA, 2000c, p. 25).

A criação do Sesp respondia às demandas dos dirigentes industriais que propunham o estabeleci- mento de escolas profissionais para contrapor-se à formação profissional dos trabalhadores adquirida pela experiência e a dos operários estrangeiros. Nas palavras de Mange,

Este avultado contingente de operários mecânicos compõe-se na sua maioria de elementos que se formaram num preparo básico, tendo adquirido apenas noções de ofício, e isso ainda dependendo da boa vontade dos operários mais antigos, herdando destes mestres improvisados com suas qualidades eventuais e também seus defeitos e vícios nos métodos de trabalho, exercendo sua profissão sem dela assumir responsabilidade, ou [...] operários estrangeiros que se dizem formados, mas cujo valor é lícito duvidar. (MANGE apud CAETANO, 1986, p. 247).

Os responsáveis pelas atividades desenvolvidas em torno da instrução racional e do movimento pela administração científica se organizaram em torno do projeto de fundação de um Instituto de Organização Científica do Trabalho em São Paulo, que desembocou na criação, em 1931, do Instituto de Organização Racional do Trabalho - Idort, com o patrocínio da Associação Comercial e da Federação das Indústrias de São Paulo:

O Idort apresentava o taylorismo como solução universal, propugnando o combate à desorganização administrativa das empresas, à utilização inadequada de matérias-primas, de força de trabatho e de energia motriz, assim como defendendo a implantação de um controle eficiente dos custos. A redução dos custos permitiria a elevação da produtividade [...] Para que a produtividade geral se elevasse seria necessário, também, aumentar a produtividade dos trabalhadores em termos físicos, para o que seriam indispensáveis os exames psicotécnicos, permitindo colocar "o homem certo no lugar certo" e selecionar os mais capazes; e o ensino sistemático de ofícios apressando e barateando a formação profissional. (CUNHA, 2000a, p. 97).

A partir da experiência acumulada com a EPM e a Sesp, Roberto Mange elaborou um plano para organizar o Centro Ferroviário de Ensino e Seleção Profissional (Cfesp), que foi criado em 1934 por decreto estadual, e constituído pelas ferrovias e pelo governo do estado de São Paulo. O Cfesp prestava serviços de seleção de pessoal, assistência técnica e coordenação da aprendizagem sistemática nas escolas profissionais existentes junto às oficinas gerais, 
em diversos pontos do estado. Para uso comum, valia-se das instalações do Sesp em Sorocaba e em São Paulo. Em 1942, existiam 16 escolas profissionais nas ferrovias paulistas, todas ligadas ao Centro.

O Cfesp distinguia-se das outras escolas de aprendizagem de ofício por serem seus alunos selecionados (em geral filhos de ferroviários) e formados com o objetivo específico para o trabalho nas estradas de ferro. O Centro tinha um método de formação de operários, as séries metódicas que eram utilizadas na Escola Profissional de Mecânica no Liceu de Artes e Ofícios de São Paulo e no Sesp. Nas outras escolas de aprendizagem de ofício, o ensino era distante das empresas, sem atender às demandas do avanço técnico verificado nas indústrias da época. Os alunos atendidos por essas escolas eram, em geral, órfãos, desvalidos, cumprindo assim a função assistencialista atribuída a essas escolas. Elas utilizavam (CUNHA, 2000c) o método de ensino artesanal, de maneira empírica, que se processava por meio da prática do aluno junto com o mestre:

Os cursos profissionais estaduais caracterizavam-se por fornecer os chamados "conhecimentos técnicos gerais", com o intuito de formar o trabalhador que possuísse o domínio do "ofício por inteiro", isto é, que possuísse habilidade e conhecimento do processo de trabalho em suas múltiplas operações e que exercesse suas atividades nos mais variados ramos produtivos. Já o ensino ferroviário orientado, coordenado e controlado pelo Cfesp tinha por finalidade o fornecimento de conhecimentos técnicos específicos vinculados diretamente à organização do processo de trabalho nas ferrovias. Aí, o ofício já apresentava-se bem parcializado e o conjunto de operações exigidas para a realização do produto apresentava-se já codificado em operações bem definidas e distintas uma das outras, possibilitando a sua reconstrução "científica" pelos responsáveis administrativos das empresas. (CAETANO, 1986, p. 271).

O avanço na aplicação da organização científica do trabalho no ensino técnico provocou, ao longo da década de 1920, o debate ${ }^{3}$ sobre a qualificação

\footnotetext{
${ }^{3}$ Fernando de Azevedo elaborou um "inquérito" sobre os problemas do ensino em todos os níveis e modalidades. Foram enviados questionários a algumas personalidades do estado de São Paulo ligadas ao problema do ensino. Fernando de Azevedo concluiu seu "inquérito" apresentando diretrizes para a solução do problema educacional paulista e brasileiro. Depois de publicado em $O$ Estado de S. Paulo (11 jun. 1926), esse "inquérito" deu origem ao livro $A$ educação na encruzilhada.
}

do trabalhador, contrapondo duas posições. Uma era representada pelos defensores da formação integral do operário, liderada por Aprígio Gonzaga, diretor do Ensino Profissional no estado e radicalmente contra a especialização da formação profissional. A outra, dos liberais reformadores e dos educadores da renovação educacional, liderada por Roberto Mange, defendia a racionalização da educação, em especial a profissional, com o objetivo de garantir a qualificação no menor tempo, em número e tipo de trabalhadores requisitados pelas indústrias (MORAES, 1990, p. 229).

No início da década de 1930, a hegemonia dos liberais reformadores e dos educadores da renovação educacional possibilitou que as contribuições de Roberto Mange fossem introduzidas na rede pública de ensino profissional por meio do Código de Educação implantado por Fernando de Azevedo em 1933:

O código de Educação de 1933 vem em resposta, a nível institucional, ao debate, que atravessa os meios intelectuais do país, sobre a questão da racionalização ou sobre o "melhor modo possível de produzir", que economize tempo, dinheiro e evite o desperdício de recursos (meios) para se atingir o fim. Na educação, este debate se cristalizou no Código. Com ele muda-se a estrutura de cursos oferecidos pelas escolas profissionais. Alteram-se as denominações das escolas da capital para institutos profissionais e para escolas profissionais secundárias, as do interior. Equiparam-se as escolas profissionais às acadêmicas. (RIBEIRO, 1986, p. 145).

Para Moraes, o Código concretizava a proposta dos reformadores para a carreira do magistério ao promover

A substituição dos "antigos mestres", geralmente de origem estrangeira e formados empiricamente nas oficinas e, por isso mesmo, portadores de graves vícios técnicos e de valores perniciosos [...] por novos mestres, "cientificamente preparados", dentro dos preceitos pedagógicos modernos, exerceria benéfica influência sobre seus futuros alunos. (MORAES, 1990, p. 228).

O Código expressava, também, a superação da defesa da educação integral do operário por uma nova realidade imposta às escolas profissionalizantes, de modo a atender à demanda das fábricas por operários qualificados e em quantidade: 
A fábrica tornara-se presença dominante na sociedade. $\mathrm{O}$ discurso e as práticas racionalizadoras nascidas no espaço fabril atingem o universo social como um todo. A crescente racionalização da produção significa o controle e homogeneização do conhecimento do trabalhador de maneira a permitir a intercambialidade de operários fora da estrutura de ofícios. Neste processo, os tempos de produção, os movimentos do trabalhador e os métodos de ensino são padronizados de forma a intensificar o trabalho; e, opera-se a seleção dos trabalhadores de acordo com padrões determinados de inteligência e aptidões. (MORAES, 1990, p. 229).

$\mathrm{O}$ acelerado processo de industrialização de São Paulo e as transformações nas relações de produção foram determinantes nas mudanças do projeto pedagógico das escolas profissionais paulistas, de tal forma que o programa de formação integral do trabalhador foi superado, passando a ser predominante a qualificação especializada de alunos selecionados por critérios científicos, bem como o requisito de contratação de professores qualificados para o ensino profissional. Nesse sentido,

[...] as propostas de Mange procuravam se adequar à realidade imposta pela fábrica, isto é, a preparar operários em quantidade e em qualidade requeridas pelo parque industrial no país. Seus métodos foram aplicados no ensino ferroviário, que funcionavam nas escolas profissionais de São Paulo, e alcançaram maior amplitude e sistematização com a estruturação do Centro Ferroviário de Ensino e Seleção Profissional. Este empreendimento pedagógico, de iniciativa comum do governo de estado e das companhias ferroviárias, seria - como se sabe o núcleo-matriz dos métodos e processo pedagógicos do Senai, criado em 1942. Pode-se afirmar que o Senai é o fruto de um projeto longamente acalentado não apenas por Mange, mas por vários integrantes do grupo liberal-reformador. (MORAES, 1990, p. 229).

Estando consolidado o novo processo de ensino técnico conduzido no Cfesp, a aprendizagem sistemática de ofício foi generalizada em nível nacional, influenciando, no início da década de 1940, as reformas educacionais que reorganizaram o sistema educacional brasileiro (CUNHA, 2000c).

Com a expansão do processo de industrialização na década de 1940, por causa da fase de intensificação da substituição de importação de mercadorias, surge a grande indústria, que fabrica "produtos intermediários (aço, alumínio, cimento, vidro, papel, plástico etc.), bens duráveis de consumo (automóveis, eletrodomésticos, televisores etc.) e bens de capital (máquinas, motores, caminhões, navios, aviões, tratores etc.)" (SINGER, 1988, p. 59).

Esta nova etapa da industrialização passou a absorver um significativo contingente de operários qualificados para operar, dar manutenção e reparar os equipamentos, assim como, em quantidades menores, os "técnicos e pessoal administrativo, com escolaridade secundária ou superior, que se encarrega de tarefas de planejamento e controle" (SINGER, 1988, p. 60).

Esse contexto de demanda por mão de obra qualificada levou o governo aprovar a Lei Orgânica do Ensino Industrial em 1942, criando assim as bases para a organização de um "sistema de ensino profissional para a indústria, articulando e organizando o funcionamento das escolas de aprendizes artífices" (KUENZER, 1987, p. 7).

Em vista da falta de recursos públicos para promover a expansão do ensino tecnoindustrial, o governo do Estado Novo transferiu para o setor privado a responsabilidade pela formação profissional das "classes menos favorecidas", por meio da inclusão, na Carta Constitucional de1937, da obrigação de as empresas e sindicatos patronais criarem escolas de aprendizes destinadas aos filhos de seus operários ou de seus associados (CUNHA, 2000c, p. 28).

Apesar das resistências iniciais do empresariado em assumir esses encargos com o ensino profissional industrial, após longas discussões foi estabelecido com o governo um acordo que consistia

[...] na instituição da aprendizagem industrial remunerada, na criação de um órgão privado encarregado de ministrar cursos em nome de todas as empresas, mediante ato do governo, mas dirigido pelos próprios industriais, financiado com recursos recolhidos pelos empresários via institutos de aposentadorias e pensões. (CUNHA, 2000c, p. 33).

Assim, por meio do Decreto-lei 40.048, de 22 de janeiro de 1942, foi criado o Serviço Nacional de Aprendizagem Industrial - Senai, marcando o início e a oficialização da transferência para o setor privado da responsabilidade pela formação e qualificação 
da mão de obra necessária para a expansão da industrialização.

A criação do Senai consolidava o projeto do setor produtivo de ter um sistema de ensino tecnoprofissional sob a sua administração, porém financiado com recursos deduzidos do Estado, por meio da retenção de impostos:

[...] o Senai assumiu a organização jurídico-administrativa que o colocava fora do Estado por interferência dos seus dois idealizadores paulistas, Roberto Simonsen e Roberto Mange. Eles tiraram o Senai da órbita de subordinação do Ministério da Educação. Este perdeu o controle sobre o ensino industrial, depois da criação do Senai. A entidade patronal dos industriais, CNI - Confederação Nacional da Indústria, irá se responsabilizar pelo processo de qualificação da força de trabalho, longe da direção e orientação pedagógica pretendida pela Superintendência do Ensino Profissional. (RIBEIRO, 1986, p. 159).

Cunha (2000c) ressalta que, naquele momento histórico, os trabalhadores não foram consultados ou convidados a participar das discussões sobre a criação do sistema de ensino industrial, nem por meio de suas instituições representativas, tendo em vista que os sindicatos estavam sob o controle do governo.

Os empresários foram obrigados, pelo governo ditatorial de Vargas, a aderir ao sistema de formação de seus operários, sendo que, passados alguns anos, uma vez constatados os resultados positivos da aprendizagem sistemática e da contribuição compulsória para os interesses dos industriais, estes reescrevem a história, assumindo a autoria da ideia de criação do sistema de ensino tecnoprofissional (CUNHA, 2000c).

O Decreto-lei que criou o Senai foi o primeiro de um conjunto de decretos denominados Leis Orgânicas do Ensino, que estruturaram o ensino propedêutico (primário e secundário) e o ensino tecnoprofissional (industrial, comercial, normal e agrícola).

Poucos dias após a criação do Senai, em 30 de janeiro de 1942, o governo de Vargas promulgou o Decreto-lei 4.073, a Lei Orgânica do Ensino Industrial, que estabelecia as bases para a organização de um "sistema de ensino profissional para a indústria", com a finalidade de atender à demanda da economia por mão de obra qualificada. Esta lei consolidava a estrutura elitista do ensino brasileiro ao oficializar a existência de duas redes de ensino paralelas: o ensino secundário, destinado a preparar as individualidades condutoras, e o profissional, destinado a formar mão de obra qualificada para atender ao setor produtivo.

Com a implantação da Lei Orgânica do Ensino Industrial, o Estado regulamentava o ensino profissional e deslocava todo o ensino profissional para o grau médio, enquanto o ensino primário tornava-se exclusivamente propedêutico. A Lei Orgânica mudou, também, os critérios de seleção dos alunos das escolas industriais. Assim,

[...] ao contrário das modalidades de recrutamento das escolas de aprendizes artífices, de forte conteúdo ideológico ligado ao assistencialismo, as novas escolas industriais previam a realização de "exames vestibulares" e de testes de aptidão física e mental. A pobreza deixava de ser, então, critério suficiente para o aprendizado de um ofício, embora não perdesse seu caráter necessário. A aptidão para um ofício, incluindo aí as atitudes consideradas adequadas para o desempenho de uma atividade industrial qualquer, passava a ser um fator prioritário na admissão. (CUNHA, 2000c, p. 36).

O ensino propedêutico de nível secundário foi reformado pelo Decreto-lei 4.244, de 9 de abril de 1942, a Lei Orgânica do Ensino Secundário, que extinguiu os cursos complementares, substituídos por cursos médios de $2 .^{\circ}$ ciclo, os quais passaram a ser conhecidos como cursos colegiais, nos tipos clássico e científico, com três anos de duração, com o objetivo de preparar e direcionar os estudantes para o nível superior. Vale lembrar que os cursos de formação profissional (normal, agrotécnico, comercial técnico e industrial) não permitiam o acesso ao ensino superior.

Segundo Kuenzer (1997), ao permitir que somente os cursos propedêuticos tivessem acesso ao nível superior e negar este direito aos cursos profissionalizantes, afirma-se um princípio que correspondia ao estágio de desenvolvimento das forças produtivas: o acesso ao nível superior se dá pelo domínio dos conteúdos gerais, das ciências, das letras e das humanidades, considerados como únicos saberes socialmente válidos para as funções de dirigentes. Os egressos dos cursos profissionais não tinham reconhecimento para um saber voltado a campo específico de trabalho. 
Somente no início da década de 1960 a formação profissional na escola deixou de ser vista apenas como alternativa de educação para os pobres, quando a estrutura produtiva do país já havia assumido um perfil capitalista e atribuía ao setor educacional uma parcela importante de responsabilidade no desenvolvimento econômico.

O ensino profissional de nível médio foi integrado ao sistema regular de ensino a partir da Lei de Diretrizes e Bases da Educação Nacional (Lei 4.024), instituída em 1961, quando o ensino médio foi estruturado em dois sistemas equivalentes: propedêutico, representado pelo científico (trabalho intelectual) e profissionalizante, com os cursos normal (magistério), industrial, comercial e agrícola (trabalho manual). Ficava estabelecida pela primeira vez a plena equivalência entre os cursos, apesar de não se superar a dualidade estrutural, uma vez que continuaram a existir dois ramos distintos de ensino para distintas clientelas.

\section{Referências}

ANTONACCI, M. A. M. A vitória da razão (?): o IDORT e a sociedade paulista. São Paulo: Marco Zero, 1993.

CAETANO, C. G. Qualificação e ferrovias: a experiência das escolas ferroviárias (1920-1945) In: RIBEIRO, Maria Alice Rosa (Org.). Trabalhadores urbanos e ensino profissional. 2 ed., Campinas: Editora da UNICAMP, 1986.

CUNHA, L. A. O ensino industrial manufatureiro no Brasil. Revista Brasileira de Educação, São Paulo, n. 14, mai/jun/ ago, p. 89-107, 2000a.

O ensino de ofícios nos primórdios da industrialização. São Paulo, Ed. UNESP, 2000b.

O ensino profissional na irradiação do industrialismo. São Paulo, Ed. UNESP, 2000c.

. As escolas de aprendizes artífices e a produção manufatureira. Revista da Faculdade de Educação da UFF. Niterói, ano 10, n. 1-2, janeiro/dezembro 1983.

FONSECA, C. S. F. História do ensino industrial no Brasil. Rio de Janeiro: SENAI, 1986a. v. 1 a 5.

GHIRALDELLI JUNIOR, P. Educação e movimento operário. São Paulo: Cortez; Campinas: Autores Associados, 1987.

GITAHY, M. L. C. Qualificação e urbanização em São Paulo: a experiência do Liceu de Artes e Ofícios (1873 - 1934) In: RIBEIRO, Maria Alice Rosa (Org.). Trabalhadores urbanos e ensino profissional. 2 ed., Campinas: Editora da UNICAMP, 1986.
HARDMAN, F.; LEONARDI, V. História da indústria e do trabalho no Brasil: das origens aos anos 20. 2.ed. São Paulo: Ática, 1991.

KUENZER, A. Z. Ensino de $2^{\circ}$ Grau: o trabalho como princípio educativo. 3. ed. São Paulo: Cortez, 1997.

Educação e trabalho no Brasil: o estado da questão. Brasília: INEP/MEC, 1987.

MORAES, C. S. V. A socialização da força de trabalho: instrução popular e qualificação profissional no Estado de São Paulo - 1873 a 1934. Tese (Doutorado em Sociologia). Faculdade de Filosofia, Letras e Ciências Humanas, USP, São Paulo, 1990.

NASCIMENTO, M. N. M. Ensino Médio no Brasil: determinações históricas. Publicatio UEPG: Ciências Humanas, Ciências Sociais Aplicadas, Linguística, Letras e Artes, v. 15, p. 77-87, 2007.

PICHELI, V. O IDORT enquanto proposta educacional no contexto de formação da hegemonia burguesa no Brasil (1930-1944). Dissertação de mestrado, Faculdade de Educação da UNICAMP, Campinas, SP, 1997.

RIBEIRO, M. A. R. Qualificação de forca de trabalho: a experiência das escolas profissionais do Estado de São Paulo 1911/1942 In: RIBEIRO, Maria Alice Rosa (Org.). Trabalhadores urbanos e ensino profissional. 2 ed., Campinas: Editora da UNICAMP, 1986.

SINGER, P. A formação da classe operária. 12 ed. São Paulo: Atual; Campinas, SP: Ed. Unicamp, 1988.

WEINSTEIN, B. (Re)formação da classe trabalhadora no Brasil (1920-1964). São Paulo, Cortez, CDAPH, IFAN, USF, 2000.

Recebido para publicação: 04/05/2012 Aceito para publicação: 01/06/2012 